EXPERIMENTAL STUDY

\title{
Exclusive underexpression of vitamin D receptor exon if transcripts in tumors of primary hyperparathyroidism
}

\author{
Pamela Correa, Göran Åkerström and Gunnar Westin \\ Department of Surgical Sciences, Endocrine Unit, Uppsala University Hospital, SE-751 85 Uppsala, Sweden \\ (Correspondence should be addressed to G Westin, Department of Surgical Sciences, Endocrine Unit, Uppsala University Hospital, Klinisk \\ forskningsavdelning 2, ingang 70, plan 3, lab 9, SE-75185 Uppsala, Sweden; Email: gunnar.westin@surgsci.uu.se)
}

\begin{abstract}
Objective: Primary hyperparathyroidism (pHPT) is characterized by excessive production of parathyroid hormone (PTH) due to parathyroid adenomas while uremic secondary HPT (sHPT) is caused by parathyroid hyperplasia in response to renal failure. Active vitamin D, 1,25-dihydroxyvitamin $\mathrm{D}_{3}\left(1,25-(\mathrm{OH})_{2} \mathrm{D}_{3}\right)$, with the vitamin D receptor (VDR) is involved in regulation of the calcium homeostasis together with PTH. In a feedback loop, $1,25-(\mathrm{OH})_{2} \mathrm{D}_{3}$ has a direct action on the parathyroid gland to regulate PTH transcription, PTH secretion and cell proliferation. We have previously demonstrated reduced VDR mRNA expression in parathyroid adenomas and hyperplasia of sHPT using a probe detecting all 14 variant VDR transcripts expressed in parathyroid cells. Here we have assessed which of the $5^{\prime}$-terminal exon $1 \mathrm{a}, 1 \mathrm{~d}$ and $1 \mathrm{f}$ variant VDR transcripts are reduced in pathological parathyroid glands.

Methods: The relative VDR/glyceraldehyde-3-phosphate dehydrogenase mRNA levels for each VDR exon were determined by real-time quantitative RT-PCR in five normal parathyroid glands, seventeen parathyroid adenomas and ten hyperplastic glands of sHPT.

Results: The results demonstrated exclusive underexpression of VDR exon $1 \mathrm{f}$ transcripts in parathyroid adenoma, while all measured VDR transcripts were reduced in secondary hyperplasia.

Conclusions: We suggest that exclusive underexpression of VDR exon 1f transcripts in adenomas of pHPT, which derive from a distal promoter active in tissues involved in calcium regulation by 1,25- $(\mathrm{OH})_{2} \mathrm{D}_{3}$, may either reflect a defective cell type-specific transcription factor or other physiologically important pathway(s) for tissue-specific VDR gene expression.
\end{abstract}

European Journal of Endocrinology 147 671-675

\section{Introduction}

Hyperparathyroidism (HPT) is characterized by hypercalcemia due to hypersecretion of parathyroid hormone (PTH). Monoclonality among adenomas of primary HPT (pHPT) is common and has also been associated with some hyperplastic glands of secondary HPT (sHPT) $(1,2)$. pHPT has a prevalence of $2-3 \%$ in postmenopausal women (3), whereas SHPT has become less frequent due to medical prevention in association with dialysis. The active form of vitamin $\mathrm{D}, 1,25$-dihydroxyvitamin $\mathrm{D}_{3}\left(1,25-(\mathrm{OH})_{2} \mathrm{D}_{3}\right)$, functions as the ligand for the vitamin D receptor (VDR) allowing the modulation of target gene transcription, through vitamin $\mathrm{D}$ response element(s). $1,25-(\mathrm{OH})_{2} \mathrm{D}_{3}$ is crucial in the maintenance of serum calcium and regulates parathyroid gland activity by inhibiting PTH transcription, PTH secretion and cell proliferation (4-7). Reduced VDR mRNA or protein expression has been shown to occur both in parathyroid adenomas and hyperplastic glands of sHPT (8-10). Furthermore, VDR polymorphisms are associated with development of parathyroid adenomas $(11,12)$ and VDR knockout mice acquire low bone mass, hypocalcemia, HPT and a tenfold elevation of $1,25-(\mathrm{OH})_{2} \mathrm{D}_{3}(13)$.

The human VDR gene spans more than $60 \mathrm{~kb}$, contains 14 exons and is transcribed from at least three promoters (14-17). Recently, four novel upstream exons were identified and denoted $1 \mathrm{f}, 1 \mathrm{e}, 1 \mathrm{~d}$ and $1 \mathrm{~b}$ (16). These give rise to several VDR transcripts which vary in the $5^{\prime}$-part of the mRNA $(15,16)$. The $5^{\prime}$-terminal exons $1 \mathrm{a}, 1 \mathrm{~d}$ and $1 \mathrm{f}$ are found in five, five and four different transcripts respectively, of which only two exon $1 \mathrm{~d}$ transcripts potentially encode proteins with N-terminal extensions of 50 or 23 amino acids. Recently, a novel N-terminal-extended VDR protein was detected in several cell types and was characterized by reduced transactivation activity (18). Most of the fourteen VDR transcripts have appeared to be expressed in one analyzed parathyroid adenoma (16). However, 
expression of all four transcripts that originate from exon 1f seems to be restricted to tissues with calciotrophic effects of vitamin D, such as kidney, parathyroid and an intestinal carcinoma cell line. This suggests that the distal promoter is cell type-specifically regulated (16). Previously conducted VDR mRNA expression analysis in parathyroid tumors used RNase protection with a probe located in VDR exon 9, subsequently detecting all fourteen transcripts (9). Reduced VDR mRNA levels could, however, be due to a reduction of any of the fourteen transcripts.

In order to investigate which of the different exon 1a, $1 \mathrm{~d}$ and $1 \mathrm{f}$ VDR transcripts could cause the reduced VDR expression level in parathyroid tumors, we have performed quantitative real-time RT-PCR analysis on five normal parathyroid glands, seventeen parathyroid adenomas and ten secondary hyperplastic glands.

\section{Materials and methods}

Seventeen tumors of pHPT and ten of sHPT were obtained from patients undergoing parathyroidectomy in routine clinical treatment. The patients comprised three males and fourteen females in the pHPT group and seven males and three females in the sHPT group. Biopsies of five normal parathyroid glands were also obtained of which three were normal glands from patients with parathyroid adenomas and two were inadvertently removed at operation of goitre patients. Patients operated for hyperparathyroidism secondary to uremia were all hypercalcemic and four patients received dialysis and four had undergone renal transplantation. Informed consent and approval of the local ethical committee was obtained. None of the patients included in this study had a history of familial hypercalcemia, or showed signs of multiple endocrine neoplasia or had previously received irradiation to the neck. All parathyroid tumors were histopathologically analyzed to confirm the diagnosis. Total serum calcium corrected for albumin (reference range $2.20-2.60 \mathrm{mM}$ ), intact serum $\mathrm{PTH}$ (reference range $1.3-5.8 \mathrm{pmol} / \mathrm{l}$ ) and serum creatinine (reference range 60-106 $\mu \mathrm{mol} / \mathrm{l}$ ) were analyzed preoperatively. Weights of pathological glands were measured immediately after removal of the glands.

Total RNA was extracted with TriZol Reagent (GibcoBRL, Life Technologies, Gaithersburg, MD, USA) from intra-operatively frozen tissue. According to standard procedures the RNA was treated with RQ1 DNase (Wizard; Promega, Madison, WI, USA) and proteinase K. First strand cDNA synthesis kit (Amersham Pharmacia Biotech, Uppsala, Sweden) was used for reverse transcription to cDNA. Real-time quantitative RT-PCR was carried out as previously described (19). Briefly, cDNA from the above-described subjects and reference cDNA (purified PCR fragments covering the sites for probes and primers) were amplified by PCR together with the presence of a probe tagged with a $5^{\prime}$ fluorescent reporter dye and a $3^{\prime}$ quencher dye (5'FAM-sequence3'TAMRA, Applied Biosystems, Foster City, CA, USA). During amplification, the exonuclease activity of Taq DNA polymerase cleaves the reporter dye from the probe and the fluorescence released is measured by a laser detector in the ABI Prism 7700 Sequence Detection System (Applied Biosystems). Quantification of the relative amount of target in samples was accomplished by using standard curves for each VDR transcript and glyceraldehyde-3-phosphate dehydrogenase (GAPDH). The standard fragment for each transcript was established by amplifying a purified PCR fragment covering the sites for probe and primers. All samples were analyzed in triplicate. The PCR mixture contained $5 \mu \mathrm{l}$ cDNA template, $1 \times$ TaqMan buffer $\mathrm{A}, 5.5 \mathrm{mM} \mathrm{MgCl}_{2}$, $200 \mu \mathrm{M}$ dATP, dCTP and dGTP, $400 \mu \mathrm{M}$ dUTP, $100 \mathrm{nM}$ probe, $200 \mathrm{nM}$ of each primer, $0.01 \mathrm{U}$ AmpErase UNG and 0.05 U AmpliTaqTM Gold. All reagents were supplied in the TaqMan PCR core Reagent Kit (Applied Biosystems). The sequence of primers and dual fluorogenic probes for VDR exon 9, 1f, $1 \mathrm{a}, 1 \mathrm{~d}$ and GAPDH were $\left(5^{\prime}-3^{\prime}\right)$ : exon 9 forward, cct tca cca tgg acg aca tg; exon 9 reverse, tca cgt cac tga cgc ggt ac; exon 9 probe, cct gga cct gtg gca acc aag act aca; exon $1 f$ forward, acg cag ggg ccc ggc cca ag; exon 1f reverse, gag ttg ctg agt gat gga t; exon if probe, gca gaa agg aag agg gcg gtg tgt t; exon 1a forward, tgt gcg ccg gga gcg cgg a; exon 1a probe, agc ttg tcc acc cgc cgg ccg gac; exon 1d forward, aga aaa gga gcg att ggc tg; exon 1d probe, ggt gct cag aac tgc tgg agt gga $g$ and the common reverse primer for exons 1a and 1d, cag aca ctt cag acc caa ag; GAPDH forward, gaa ggt gaa ggt cgg agt c; GAPDH reverse, gaa gat ggt gat ggg att tc and GAPDH probe, caa gct tcc cgt tct cag cc.

Values are presented as means \pm S.E.M. Differences in mean values were calculated with ANOVA followed by Fischer's PLSD using $P<0.05$ as significant. All calculations were made with StatView.

\section{Results}

In order to determine the relative contribution of $5^{\prime}$ terminal exon variant VDR gene transcripts (16) to the previously observed underexpression of VDR mRNA (exon 9), in lesions of pHPT and sHPT (9), we designed primers and probes specific for the VDR exons 1f, 1a, $1 \mathrm{~d}$ and 9 (Fig. 1). The relative VDR/GAPDH mRNA levels for each exon were determined by real-time quantitative RT-PCR in five normal parathyroid glands, seventeen parathyroid adenomas and ten hyperplastic glands of sHPT. Clinical characteristics of the patients are shown in Table 1. Compared with normal parathyroid glands, a significantly reduced level of VDR exon 9 transcripts was seen both in hyperplasias of sHPT and parathyroid 


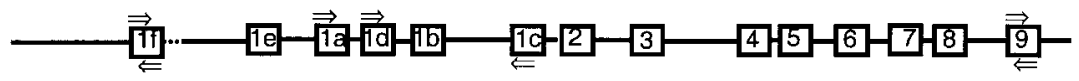

Figure $1 \mathrm{~A}$ schematic representation of the human VDR gene (not to scale). The different exons are shown. Promoters are located upstream of the non-coding exons 1f, 1a and 1c (14-17). The arrows indicate locations of the PCR primers used in this study. adenomas (Fig. 2), in agreement with published results where an RNase protection assay was used for quantification (9). In the hyperplastic glands of sHPT, levels of VDR transcripts containing exons $1 \mathrm{f}, 1 \mathrm{a}$ and $1 \mathrm{~d}$ were all significantly reduced compared with normal glands $(P<0.04$; $P<0.001)$, but in parathyroid adenomas there was no significant difference $(P>0.05)$ for exon $1 \mathrm{a}$ and exon 1d (Fig. 2). Only the level of VDR transcripts with the most distal exon $1 \mathrm{f}$ was significantly reduced $(P<0.001)$ in parathyroid adenomas compared with normal glands (Fig. 2). Thus, the reduced VDR mRNA level in adenomas reflects a specific underexpression of exon $1 \mathrm{f}$-containing transcripts. We note, however, that a few individual adenomas displayed low expression of VDR exon $1 \mathrm{~d}$ transcripts. No correlations between VDR expression level for any of the different transcripts and clinical characteristics such as gland weight, serum PTH, serum calcium or serum creatinine were found.

\section{Discussion}

In this study we have shown that VDR transcripts with the most distal exon $1 \mathrm{f}$ are exclusively underexpressed in parathyroid adenomas in contrast to hyperplastic tumors which demonstrated an overall underexpression of all three analyzed 5'-terminal variant VDR gene transcripts. Expression of the VDR gene, which consists of 14 exons, seems to be regulated by at least three promoters located upstream of the non-coding exons 1f, $1 \mathrm{a}$ and $1 \mathrm{c}(14-17)$. Interestingly, exon 1f transcripts have so far only been detected in tissues involved in calcium regulation by $1,25-(\mathrm{OH})_{2} \mathrm{D}_{3}$, such as a parathyroid adenoma, an intestinal carcinoma cell line and kidney. The distal if promoter, located approximately $9 \mathrm{kbp}$ upstream of exon $1 \mathrm{a}$, was thus suggested to regulate tissue-specific VDR gene expression
(16). The observed underexpression of exon $1 \mathrm{f}$ transcripts in parathyroid adenomas can be explained by several default mechanisms. The VDR 1f promoter may be directly involved through mutations in promoter elements or, more likely, indirectly through inactivating mutations or aberrant expression of a parathyroid transcription factor gene. Other possible mechanisms include changed mRNA stability or other physiologically important pathways for tissue-specific VDR gene expression. The VDR exon 1d transcript expression was not significantly reduced in parathyroid adenomas, although a few individual adenomas displayed low levels. This could represent reduced expression of the two exon 1d/exon 1c-containing VDR transcripts described (16), or of only the one encoding an N-terminalextended VDR protein (18). The non exon-specific down-regulation of VDR transcripts in hyperplastic glands of sHPT may be due to synergistic effects of hypocalcemia and hyperphosphatemia.

$1,25-(\mathrm{OH})_{2} \mathrm{D}_{3}$ is crucial in the maintenance of serum calcium and regulates parathyroid gland activity by inhibiting PTH transcription, PTH secretion and cell proliferation (4-7). Many of these regulatory pathways involve, or are expected to involve, the VDR. Furthermore, suboptimal vitamin D nutrition stimulates growth of parathyroid adenomas (20), and over-representation of certain VDR alleles in Caucasian patients are predictive factors for the development of pHPT $(11,12)$. Reduction of the cell type-specific VDR exon 1f transcripts in pHPT and of exon 1f, 1 a and 1d transcripts in SHPT is expected to interfere with the regulatory effects of $1,25-(\mathrm{OH})_{2} \mathrm{D}_{3}$ in the pathological glands and to contribute to parathyroid tumorigenesis. Elucidating the precise regulatory mechanisms for VDR gene expression and identification of $1,25-(\mathrm{OH})_{2} \mathrm{D}_{3}$ target genes in parathyroid glands, whose expression is sensitive to a reduced VDR level, demands further studies.

Table 1 Clinical characteristics of the patients. Values are means \pm S.E.M.

\begin{tabular}{lcccc}
\hline & Age (years) & Calcium $(\mathrm{mmol} / \mathrm{l})$ & PTH $(\mathrm{pmol} / \mathrm{l})$ & Gland weight $(\mathrm{g})$ \\
$\begin{array}{l}\text { Normal } \\
(n=5)\end{array}$ & $59.3 \pm 6.8$ & $2.62 \pm 0.29$ & ND & ND \\
$\begin{array}{l}\mathrm{pHPT} \\
(n=15)\end{array}$ & $67.4 \pm 3.5$ & $2.92 \pm 0.05$ & $12.7 \pm 2.8$ & $1.13 \pm 0.21$ \\
$\begin{array}{l}\text { SHPT } \\
(n=10)\end{array}$ & $51.1 \pm 2.6$ & $2.2 \pm 0.06$ & $83.3 \pm 22.6$ & $3.42 \pm 1.2$
\end{tabular}

The group of five normal gland biopsies consisted of three normal glands from patients with parathyroid adenomas and two inadvertently removed at operation of goitre patients. Two additional pHPT patients with ordinary clinical characteristics were included in the study.

ND, not determined. 


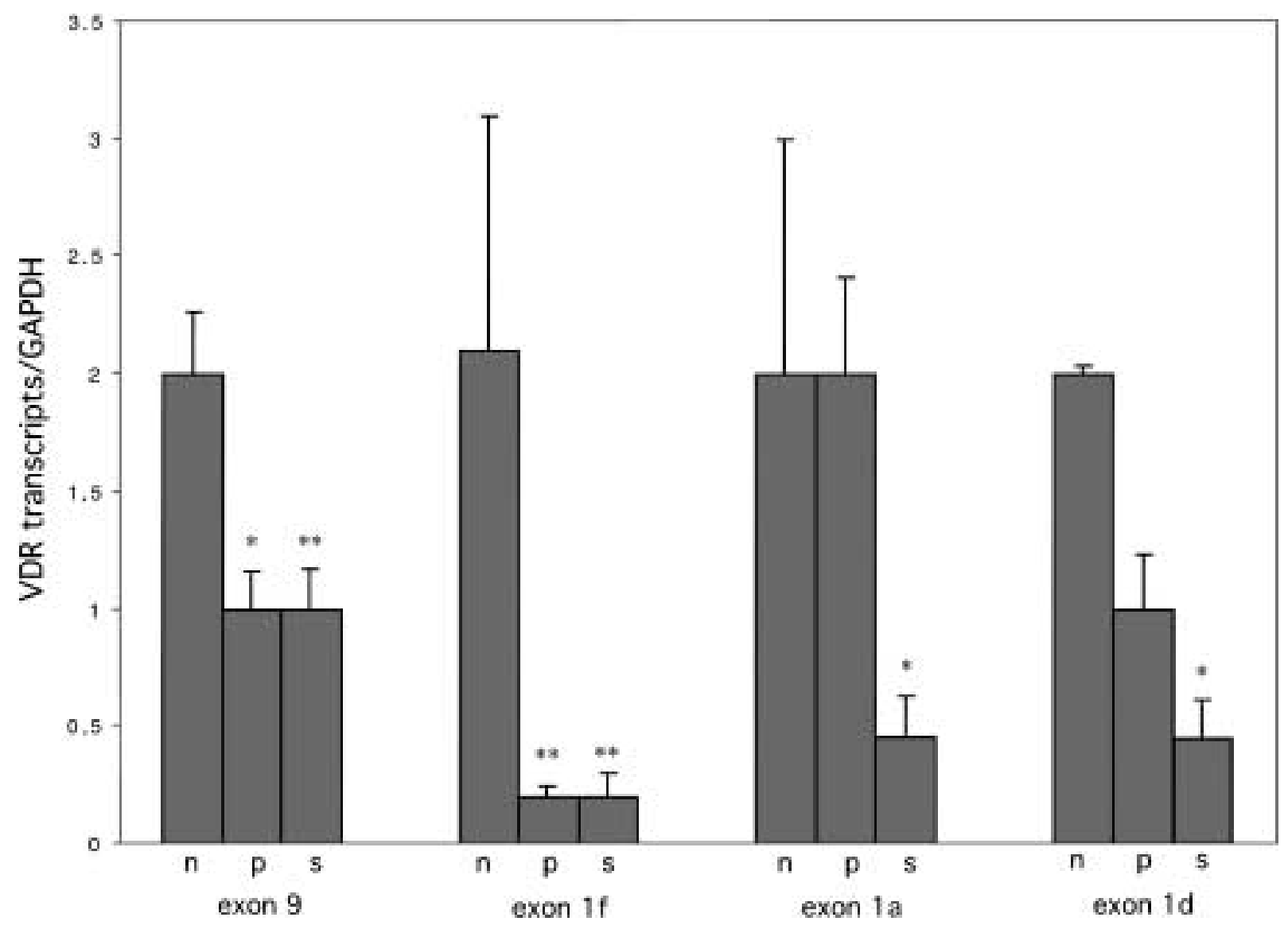

Figure 2 VDR exon 9, and $5^{\prime}$-terminal exon 1f, 1a and 1d/GAPDH mRNA ratios were determined by real-time quantitative RT-PCR in five normal parathyroid glands $(n)$, seventeen parathyroid adenomas $(p)$ and ten hyperplastic glands of sHPT (s). Values represent means \pm S.E.M. and $P$ values $\left({ }^{\star} P<0.04,{ }^{* \star} P<0.001\right)$ were calculated using ANOVA followed by Fisher's PLSD. Values represent relative expression level for each type of VDR transcript.

\section{Acknowledgements}

This work was supported by grant 12574 from the Swedish Research Council, the Swedish Cancer Society and Lions Fund for Cancer Research.

\section{References}

1 Arnold A, Staunton CE, Kim HG, Gaz RD \& Kronenberg HM. Monoclonality and abnormal parathyroid hormone genes in parathyroid adenomas. New England Journal of Medicine $1988 \mathbf{3 1 8}$ 658-662.

2 Shan L, Nakamura M, Nakamura Y, Inoue D, Morimoto S, Yokoi T et al. Comparative analysis of clonality and pathology in primary and secondary hyperparathyroidism. Virchows Archives 1997430 247-251.

3 Lundgren E, Rastad J, Thurfjell E, Åkerström G \& Ljunghall S. Population-based screening for primary hyperparathyroidism with serum calcium and parathyroid hormones values in menopausal women. Surgery $1997 \mathbf{1 2 1} 287-294$.

4 Haussler MR, Whitfield GK, Haussler CA, Hsieh JC, Thompson PD, Selznick SH et al. The nuclear vitamin D receptor: biological and molecular regulatory properties revealed. Journal of Bone and Mineral Research 199813 325-349.
5 Jones G, Strugnell SA \& DeLuca HF. Current understanding of the molecular actions of vitamin D. Physiological Reviews $1998 \mathbf{7 8}$ 1193-1231.

6 Hellman P, Liu W, Westin G, Törmä H \& Åkerström G. Vitamin D and retinoids in parathyroid glands (review). International Journal of Molecular Medicine 19993 355-361.

7 Silver J, Yalcindag C, Sela-Brown A, Kilav R \& Naveh-Many T. Regulation of the parathyroid hormone gene by vitamin D, calcium and phosphate. Kidney International 199973 (Suppl) S2-S7.

8 Fukuda N, Tanaka H, Tominaga Y, Fukagawa M, Kurokawa K \& Seino Y. Decreased 1,25-dihydroxyvitamin $\mathrm{D}_{3}$ receptor density is associated with a more severe form of parathyroid hyperplasia in chronic uremic patients. Journal of Clinical Investigation 1999 92 1436-1443.

9 Carling T, Rastad J, Szabo E, Westin G \& Åkerström G. Reduced parathyroid vitamin D receptor messenger ribonucleic acid levels in primary and secondary hyperparathyroidism. Journal of Clinical Endocrinology and Metabolism 200085 2000-2003.

10 Sudhaker Rao D, Han ZH, Phillips ER, Palnitkar S \& Parfitt AM. Reduced vitamin D receptor expression in parathyroid adenomas: implications for pathogenesis. Clinical Endocrinology 200053 373-381.

11 Carling T, Kindmark A, Hellman P, Holmberg L, Åkerström G \& Rastad J. Vitamin D receptor alleles b, a, and T: risk factors for sporadic primary hyperparathyroidism (HPT) but not of uremia or MEN 1. Biochemical and Biophysical Research Communications $1997231329-332$. 
12 Carling T, Rastad J, Åkerstrom G \& Westin G. Vitamin D receptor (VDR) and parathyroid hormone messenger ribonucleic acid levels correspond to polymorphic VDR alleles in human parathyroid tumors. Journal of Clinical Endocrinology and Metabolism 1988 $832255-2259$

13 Yoshizawa T, Handa Y, Uematsu Y, Takeda S, Sekine K, Yoshihara Yet al. Mice lacking the vitamin D receptor exhibit impaired bone formation, uterine hypoplasia and growth retardation after weaning. Nature Genetics 199716 391-396.

14 Baker AR, McDonnell DP, Hughes M, Crisp TM, Mangelsdorf DJ, Haussler MR et al. Cloning and expression of full-length cDNA encoding human vitamin D receptor. PNAS $1988 \mathbf{8 5} 3294-3298$.

15 Miyamoto K, Kesterson RA, Yamamoto H, Taketani Y, Nishiwaki E, Tatsumi S et al. Structural organization of the human vitamin D receptor chromosomal gene and its promoter. Molecular Endocrinology 199711 1165-1179.

16 Crofts LA, Hancock MS, Morrison NA \& Eisman JA. Multiple promoters direct the tissue-specific expression of novel N-terminal variant human vitamin D receptor gene transcripts. PNAS 1998 95 10529-10534.
17 Byrne IM, Flanagan L, Tenniswood MP \& Welsh J. Identification of a hormone-responsive promoter immediately upstream of exon 1c in the human vitamin D receptor gene. Endocrinology 2000141 $2829-2836$.

18 Sunn KL, Cock T-A, Crofts LA, Eisman JA \& Gardiner EM. Novel N-terminal variant of human VDR. Molecular Endocrinology 200115 1599-1609.

19 Gibson UE, Heid CA \& Williams PM. A novel method for real time quantitative RT-PCR. Genome Research 19966 995-1001.

20 Rao DS, Honasoge M, Divine GW, Phillips ER, Lee MW, Ansari MR et al. Effect of vitamin D nutrition on parathyroid adenoma weight: pathogenetic and clinical implications. Journal of Clinical Endocrinology and Metabolism 200085 1054-1058.

Received 1 March 2002

Accepted 22 July 2002 